\title{
Pre-treatment with tannic acid inhibits the intracellular IL-8 production by chitosan in a human oral epithelial cancer cell line
}

\author{
Hidetaka Ishizaki, Shizuka Yamada, Kajiro Yanagiguchi, Zenya Koyama, Takeshi Ikeda, \\ Yoshihiko Hayashi
}

Department of Cariology, Nagasaki University Graduate School of Biomedical Sciences, Nagasaki, Japan

Abstract: Chitosan stimulates the fibroblastic, endothelial, and intestinal epithelial cells to release chemotactic inflammatory cytokines, especially interleukin 8 (IL-8). Tannic acid (TA) has a variety of biological activities, such as anti-inflammatory, anti-viral effects. However, the pre-treatment of TA on chitosan polymer-induced IL-8 production from epithelial cells has not been well studied. This study focused on the effect of TA on chitosan polymer-induced IL-8 production in the oral mucosal epithelium as estimated by HSC-2 cells established from a human oral squamous cell carcinoma. The intracellular IL-8 production was measured by flow cytometry. The chitosan polymer-induced production of IL-8 decreased after pre-treatment with TA. IL-8 mRNA was measured by real-time PCR, and its mRNA expression level was reduced after TA pre-treatment. Antibody-based assays were used to investigate the effect of chitosan and TA on the activation of mitogen-activated protein kinases (MAPKs). These investigations showed the pre-treatment effects of TA on IL-8 production to be mainly mediated through the inhibition of the $\mathrm{p} 38$ MAPK pathways. The present study demonstrated that TA pre-treatment reduced the intracellular IL-8 production in HSC-2 cells via the MAPK signaling pathways. These findings indicate that the combined application of TA and chitosan may be clinically beneficial for the inflammatory lesions of the oral mucosa.

[Oral Med Pathol 2009; 13: 135-141 doi: 10.3353/omp.13.135]

Key words: chitosan polymer, tannic acids, IL-8, oral epithelial cell line, MAPK pathways

Correspondence: Yoshihiko Hayashi, Department of Cariology, Nagasaki University Graduate School of Biomedical Sciences, Sakamoto 1-7-1, Nagasaki 852-8588, Japan Phone: 81-95-819-7679, Fax: 81-95-819-7680, E-mail: hayashi@nagasaki-u.ac.jp

\section{Introduction}

Chitosan has a variety of biological activities and is advertised as a healthy food that is effective in the improvement and/or care of various disorders, such as arthritis, cancer, diabetes, hepatitis, etc (1-2). It also accelerates wound healing, and helps to achieve a pleasant-looking skin surface and prevents excess scar formation (3-4).

Chitosan has been widely used as an effective medicament in various fields of medicine and dentistry (5-6). In endodontics, it can be used as an anti-inflammatory root canal dressing material for periapical lesions (7). Chitosan has also been applied clinically as a dressing for oral mucosal wounds and as a tampon following the radical treatment of maxillary sinusitis. Chitosan stimulates the fibroblastic, endothelial, and intestinal epithelial cells to release chemotactic inflammatory cytokines, especially IL-8 (8-10). IL-8 is a major chemokine for neutrophils which are largely responsible for phagocytosis at the initial inflammatory sites. Actinobacillus actinomycetemcomitans plays an important role in initiating inflammatory reaction through the release of IL-8 from gingival epithelial cells (11). The mRNA level of human IL-8 is elevated by live cultures of a clinical isolate of Aggregatibacter actinomycetemcomitans in cultured gingival epithelial cells from healthy individuals (12). The histological findings indicate that chitosan induces the migration of polymorphonuclear leukocytes and macrophages in the applied tissue at an early stage (13). Therefore, the initial inflammatory reactions must be overcome before the chitosan can be clinically applied to gingival wounds.

Tannic acid (TA) has anti-oxidant, anti-inflammatory, and anti-carcinogenic properties (14-17). TA reduced UVB induces IL-18 production from human keratinocyte cell line, $\mathrm{HaCaT}$, and TA regulates the p38 mitogen-activated protein kinase (MAPK) and ERK (18). Cranberry components (polyphenolic rich fruit) inhibit IL-6, IL-8, and prostaglandin E2 produced by lipopolysaccharide-activated gingival fibroblasts (19). However, the anti-inflammatory properties of TA on chitosan-induced IL-8 production from epithelial 
cell have not been well studied.

The aim of this study was to investigate the effect and the sub-cellular mechanism of TA on the production of IL-8, an inflammatory mediator, by HSC- 2 cells stimulated by chitosan polymer. This model system may therefore suggest a new application of TA to suppress the initial inflammation by chitosan dressing on the oral mucosa.

\section{Materials and methods}

\section{Preparation of chitosan and TA}

The chitosan polymer used in this study was supplied by Tokyo Kasei Kogyo Co., Ltd. (Tokyo, Japan). The degree of deacetylation of chitosan was $88.8 \%$. Its molecular weight was approximately $580 \mathrm{KDa}$. A $0.5 \%(\mathrm{w} / \mathrm{v})$ solution of chitosan polymer was prepared by dissolving chitosan polymer powder in $0.4 \%(\mathrm{v} / \mathrm{v})$ acetic acid. The completely dissolved solution was neutralized to $\mathrm{pH} 7.4$, and was then filtered using a $0.45 \mu \mathrm{m}$ filter. A $0.4 \%$ acetic acid solution (pH 7.4) was used as a control solution.

The TA was obtained from Wako Pure Chemical Industries, Ltd. (Osaka, Japan). The molecular weight of the TA used in this study was about 250-4,000 Da. A 0.5\% (w/v) solution was prepared by dissolving powdered TA in ultrapure water. The completely dissolved solution was neutralized to $\mathrm{pH} 7.4$ and was then filtered using a $0.2 \mu \mathrm{m}$ filter.

\section{Cell culture}

A cell line, HSC-2 established from a human oral squamous cell carcinoma, was purchased from the Human Science Research Resources Bank (HSRRB, Osaka, Japan). The HSC-2 cells were seeded at $5 \times 10^{5}$ cells per $100 \mathrm{~mm}$ culture dish and maintained in $9 \mathrm{ml}$ of Eagle's alpha minimum essential medium ( $\alpha$-MEM) supplemented with $10 \%$ fetal bovine serum (FBS), $100 \mathrm{U} / \mathrm{ml}$ penicillin and 100 $\mu \mathrm{g} / \mathrm{ml}$ streptomycin. The cells were cultured in a humidified atmosphere of $95 \%$ air with $5 \% \mathrm{CO}_{2}$ at $37^{\circ} \mathrm{C}$. The medium was replaced every 3 days. HSC- 2 cells between passages 6 and 9 were used for this experiment.

\section{IL-8 production assay}

HSC- 2 cells were seeded in a $35 \mathrm{~mm}$ culture dish at a density of $5 \times 10^{5}$ cells in $\alpha$-MEM. A $0.5 \%(\mathrm{w} / \mathrm{v})$ solution of chitosan polymer was diluted to prepare $0.2,0.1,0.05$, $0.025,0.01$, and $0.005 \%(\mathrm{w} / \mathrm{v})$ solutions. After the cells were seeded, $2 \mathrm{mM}$ of monensin (EMD Chemicals Inc., Gibbstown, NJ, USA) for blocking the protein transportation from the Golgi body to the cytoplasm and the chitosan polymer solution was added to the medium. After 2 to $8 \mathrm{hrs}$ of culture with or without chitosan, cells were scraped off from the dishes with a rubber policeman. In order to assess the inhibitory effect of TA in chitosan polymer-induced IL-8 production, HSC-2 cells were cultured with $0.0005 \%$,

Table 1. Effects of chitosan polymer and tannic adid (TA) on relative levels of phosphorylation of various kinases.

\begin{tabular}{|c|c|c|c|c|}
\hline \multicolumn{2}{|l|}{ protein } & \multirow[b]{2}{*}{ phosphorylation sites } & \multicolumn{2}{|c|}{ ratio $^{\mathrm{a}}$} \\
\hline full name & abbreviation & & $\begin{array}{l}\text { unstimulated } \\
\text { vs. chitosan }\end{array}$ & $\begin{array}{l}\text { TA+chitosan } \\
\text { vs. chitosan }\end{array}$ \\
\hline extracellular signal-regulated kinase 1 & ERK1 & T202/Y204 & 1.1 & 0.9 \\
\hline extracellular signal-regulated kinase 2 & ERK2 & $\mathrm{T} 185 / \mathrm{Y} 187$ & 1.8 & 0.9 \\
\hline Jun N-terminal protein-serine kinases 1 & JNK1 & & 1.3 & 0.9 \\
\hline Jun $\mathrm{N}$-terminal protein-serine kinases 2 & JNK2 & 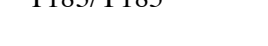 & 1.6 & 0.9 \\
\hline Jun N-terminal protein-serine kinases 3 & JNK3 & $\mathrm{T} 221 / \mathrm{Y} 223$ & 1.3 & 0.8 \\
\hline Jun N-terminal protein-serine kinases pan & JNKpan & $\begin{array}{l}\mathrm{T} 183 / \mathrm{Y} 185 \\
\mathrm{~T} 221 / \mathrm{Y} 223\end{array}$ & 1.8 & 0.9 \\
\hline mitogen- and stress-activated protein kinase 2 & MSK2 & S360 & 1.4 & 0.6 \\
\hline p38 Mitogen-activated protein kinase $\alpha$ & $\mathrm{p} 38 \alpha$ & $\mathrm{T} 180 / \mathrm{Y} 182$ & 2.2 & 0.8 \\
\hline p38 Mitogen-activated protein kinase $\beta$ & $\mathrm{p} 38 \beta$ & & 1.6 & 1.0 \\
\hline p38 Mitogen-activated protein kinase $\gamma$ & $\mathrm{p} 38 \gamma$ & $\mathrm{T} 183 / \mathrm{Y} 185$ & 1.5 & 0.7 \\
\hline p38 Mitogen-activated protein kinase $\delta$ & p38d & $\mathrm{T} 180 / \mathrm{Y} 182$ & 1.6 & 0.8 \\
\hline ribosomal S6 kinase 1 & RSK1 & S380 & 1.3 & 0.9 \\
\hline ribosomal S6 kinase 2 & RSK2 & S386 & 1.1 & 0.8 \\
\hline glycogen synthase kinase $-3 \alpha / \beta$ & GSK- $3 \alpha / \beta$ & S21/S9 & 1.7 & 0.5 \\
\hline glycogen synthase kinase- $3 \beta$ & GSK-3 $\beta$ & S9 & 1.6 & 0.8 \\
\hline heat shock protein 27 & HSP27 & S78/S82 & 0.7 & 1.0 \\
\hline serine-threonine kinase 1 & Akt1 & S473 & 1.8 & 0.6 \\
\hline serine-threonine kinase 2 & Akt 2 & S474 & 1.1 & 0.7 \\
\hline serine-threonine kinase 3 & Akt3 & S472 & 1.1 & 0.7 \\
\hline serine-threonine kinase pan & Akt pan & S473/S474/S472 & 1.2 & 0.6 \\
\hline
\end{tabular}

${ }^{a}$ Confirmed by densitometric value. Data are from duplicate samples. 


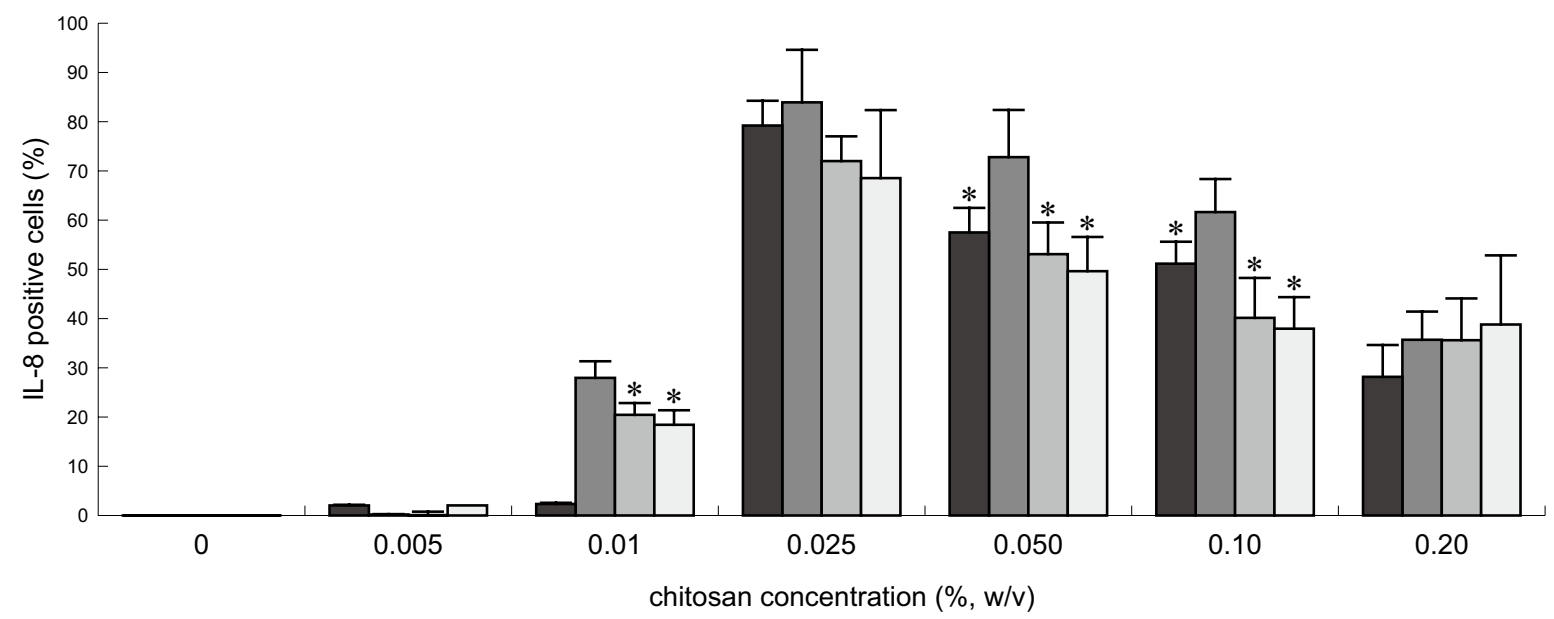

Fig. 1. The effect of treatment with chitosan polymer on the production of IL- 8 in HSC-2 cells. The data are the mean \pm standard deviations (SD) of the triplicate assays at $2, \square ; 4, \square ; 6, \square ; 8, \square$ hrs. ${ }^{*} P$-value of $<0.05$ compared to 4 hrs of incubation group. The largest production of IL-8 was shown after the incubation with $0.025 \%$ of chitosan.

$0.001 \%$ and $0.002 \%(\mathrm{w} / \mathrm{v})$ of TA for $2 \mathrm{hrs}$ before the application of chitosan. After the treatment, phosphatebuffered saline(-) was added to the scraped cells, which were centrifuged at $300 \times g$ for $5 \mathrm{~min}$. Cell pellets were treated by IntraPrep Reagent 1 (Beckman Coulter Inc., Fullerton, CA, USA) at room temperature for $15 \mathrm{~min}$ to fix the cells. After the treatment, the cells were collected in PBS(-) and centrifuged at $300 \times g$ for $5 \mathrm{~min}$. The cell pellet was treated by IntraPrep Reagent 2 (Beckman Coulter) at room temperature for $5 \mathrm{~min}$ to regulate the membrane's permeability. After the treatment, FITC-labeled anti-human IL-8 antibodies (R\&D Systems Europe Ltd., Abingdon, UK) or anti-mouse IgG1-FITC as an isotype control were added and incubated at room temperature for $15 \mathrm{~min}$ in a dark area. After adding PBS(-), the reacted sample was centrifuged at $300 \times g$ for $5 \mathrm{~min}$. The cell pellet was suspended in PBS(-) supplemented with $0.5 \%(\mathrm{w} / \mathrm{v})$ paraformaldehyde. 10,000 cells/sample were analyzed using EPICS XL flow cytometer (Beckman Coulter), which was equipped with an argon laser, at a wavelength of $488 \mathrm{~nm}$.

\section{Isolation of RNA}

HSC-2 cells were seeded in a $60 \mathrm{~mm}$ culture dish at a density of $5 \times 10^{5}$ cells and cultured for 2 or $4 \mathrm{hrs}$ in $\alpha$-MEM containing $10 \%$ FBS supplemented with $0.025 \%(\mathrm{w} / \mathrm{v})$ chitosan polymer, or chitosan polymer and $0.001 \%(\mathrm{w} / \mathrm{v})$ TA. The cells were rinsed twice with PBS(-) and scraped off from the dishes. The total RNA was prepared using an Atlas $^{\mathrm{TM}}$ Glass Total RNA Isolation kit (Takara Bio Inc., Otsu, Japan), according to the instructions provided by the manufacturer.

\section{RT-PCR}

HSC- 2 cells were seeded in a $60 \mathrm{~mm}$ culture dish at a density of $5 \times 10^{5}$ cells and cultured for 2 or $4 \mathrm{hrs}$ in $\alpha$-MEM containing $10 \%$ FBS supplemented with $0.025 \%(\mathrm{w} / \mathrm{v})$ chitosan polymer, or $0.001 \%(\mathrm{w} / \mathrm{v})$ of $\mathrm{TA}+$ chitosan polymer. In order to investigate the effects of the chitosan polymer-induced IL- 8 production via the MAPK signaling pathways, HSC-2 cells were pretreated with either an upstream inhibitor of extracellular signal-regulated kinase (ERK) (PD98059) or p38 MAPK (SB203580) at a concentration of $10 \mu \mathrm{M}$ for $2 \mathrm{hrs}$ prior to the chitosan exposure. These specific inhibitors were purchased from EMD Chemicals. After the HSC-2 cells were incubated, they were rinsed twice with PBS(-). Total RNA was extracted using Trizol ${ }^{\circledR}$ regent (Life Technologies Inc., Carabad, CA, USA), according to the manufacturer's instructions. cDNA synthesis was performed using a SuperScript ${ }^{\mathrm{TM}}$ First-Stand Synthesis System (Life Technologies) and an oligo dT according to manufacturer's instructions. cDNA obtained from $400 \mathrm{ng}$ of the total RNA was used for one PCR. For amplification of IL-8 via PCR, the forward primer sequence was 5'-ATGAC TTCCA AGCTG GCCGT GGCT-3', and the reverse one was 5'-TCTCA GCCCT CTTCA AAAAC TTCTC-3' (20). For glyceraldehyde phosphate dehydrogenase (GAPDH), the forward primer sequence was 5'-CGGAG TCAAC GGATT TGGTC GTAT-3', and the reverse one was 5'-ACCCT TCTCC ATGGT GGTGA AGAC-3' (20). A master mix of the following PCR reaction components was prepared to the indicated quantity: $9.1 \mu \mathrm{l}$ of water, $0.3 \mu \mathrm{l}$ of diluted reference dye, $0.2 \mu \mathrm{l}$ of forward and reverse primers and $10 \mu \mathrm{l}$ of Brilliant ${ }^{\circledR} \mathrm{SYBR}^{\circledR}$ Green QPCR Master Mix (Stratagene, La Jolla, CA, USA). The abovementioned reaction was placed in a $0.2 \mathrm{ml}$ tube and $0.2 \mu \mathrm{l}$ of cDNA was added as the PCR template for amplification via PCR. The PCR sequence protocol was as follows: an initial denaturation at $95^{\circ} \mathrm{C}$ for $10 \mathrm{~min} ; 30$ cycles were conducted, each cycle consisting of $15 \mathrm{sec}$ of denaturation at $94^{\circ} \mathrm{C}, 18$ sec of annealing at $55^{\circ} \mathrm{C}$ and $45 \mathrm{sec}$ of extention at $72^{\circ} \mathrm{C}$; and a final step of $72^{\circ} \mathrm{C}$ for $1 \mathrm{~min}$. The amplification and date acquisition were carried out using an Mx3000P QPCR machine (Stratagene).

The quantification was accomplished by determining the threshold cycle (the second derivative of the resulting fluorescence curve) at which the amplicon is detected during the PCR and comparing this to the standard curve calculated from the parallel quantification reactions. These calculations 


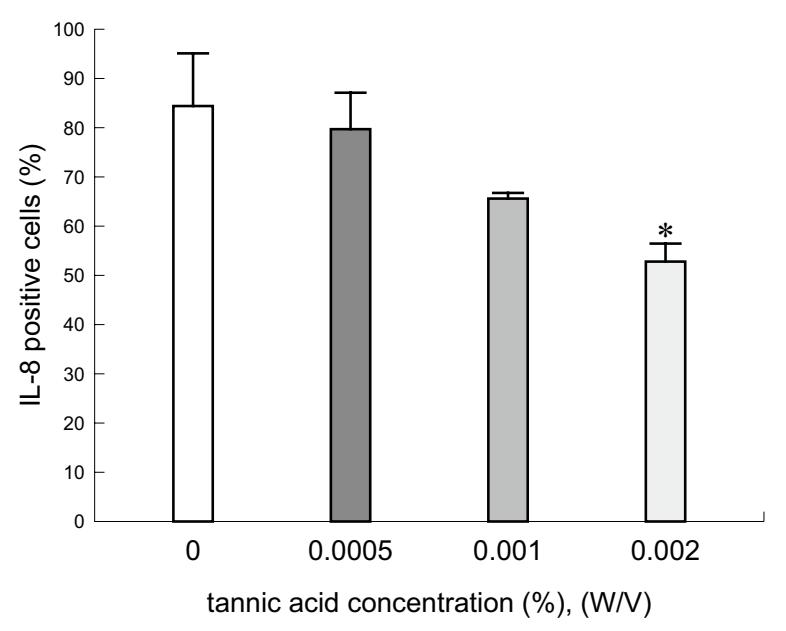

Fig. 2. The effect of pre-treatment with tannic acid (TA) for 2 hrs on the production of chitosan $(0.025 \%, 4 \mathrm{hrs})$ induced IL-8 in HSC-2 cells. The data are the mean \pm $\mathrm{SD}$ of the triplicate assays. $* P$-value of $<0.05$ compared to the untreated control. An effective inhibition was observed at a $0.001 \%$ of TA.

were done with the comparative quantification method using the Stratagene form. These data were normalized by GAPDH.

\section{Antibodies assay for phosphorylation of MAPKs}

HSC-2 cells were seeded in $100 \mathrm{~mm}$ culture dish at a density of $5 \times 10^{5}$ cells. After 10 days of culture, HSC- 2 cells sub-confluent in dish were pre-treated with $0.001 \%$ of TA for $2 \mathrm{hrs}$ and were then treated with $0.025 \%$ chitosan polymer for $30 \mathrm{~min}$. The cells were retrieved and lysed following the manufacturer's instructions.

The relative level of phosphorylation of various signal transduction kinases was analyzed using a human MAPK array kit (R\&D) (21). Phospho-site specific biotinylated antibodies (Table 1) were used to detect twenty different kinds of phosphorylated kinases via streptoavidin-HRP, and then the membranes were exposed to X-ray film and the detected signals were developed on film. Thereafter, each signal was quantitatively measured using a densitometric mode of ChemiImager ${ }^{\mathrm{TM}}$ (Alpha Innotec Corp., San Leandro, CA, USA).

\section{Statistical analysis}

The statistical significance was determined by means of Fisher's PLSD test and the StatView software program (SAS Institute Inc., Cary, NC, USA). The results were considered to be statistically significant with a $P$ value of $<0.05$.

\section{Results}

\section{IL-8 production}

Chitosan polymer stimulated the IL-8 production in HSC-2 cells (Fig. 1). The incubation of these cells with $0.025 \%(\mathrm{w} / \mathrm{v})$ of chitosan polymer for $4 \mathrm{hrs}$ induced the largest production of IL-8. The chitosan polymer-induced production of IL-8 from HSC-2 cells was reduced by a pretreatment with TA (Fig. 2). This inhibition was dependent on the concentration of TA. Since the $0.002 \%$ of TA also inhibited the cell viability, thus the inhibitory effect of TA on the mRNA level was examined at $0.001 \%$.

\section{RT-PCR}

The IL-8 mRNA expression level by chitosan polymer was reduced after 2 hrs of TA pre-treatment (Fig. 3). The extent of the inhibitory reaction was similar at 2 and $4 \mathrm{hrs}$ of chitosan application. The $4 \mathrm{hrs}$ of incubation was used for the next experiment, because cell damage did not occur by the longer application of chitosan.

Although there was no statistical difference, the pretreatment of specific inhibitors for MAPK pathways, PD98059 or SB 203580, effectively reduced IL-8 mRNA expression level in comparison to the chitosan polymer group (Fig. 4). The inhibitory reaction was recognized at a similar level between $\mathrm{TA}$ and the specific inhibitor applications.

\section{Antibodies assay for phosphorylation of MAPKs}

The expression of various phosphorylated kinases in the chitosan polymer group or TA and the chitosan group compared to the control group is shown in Table 1. Fifteen kinases exhibited a difference ratio between chitosan polymer group and the unstimulated group of $\geq 1.2$. The ratios of ERK2, JNK1, JNK2, JNK3, JNK pan, MSK2, p38g, p38d, p38a, p38b, RSK1, GSK-3a/b, GSK-3b, Akt1,
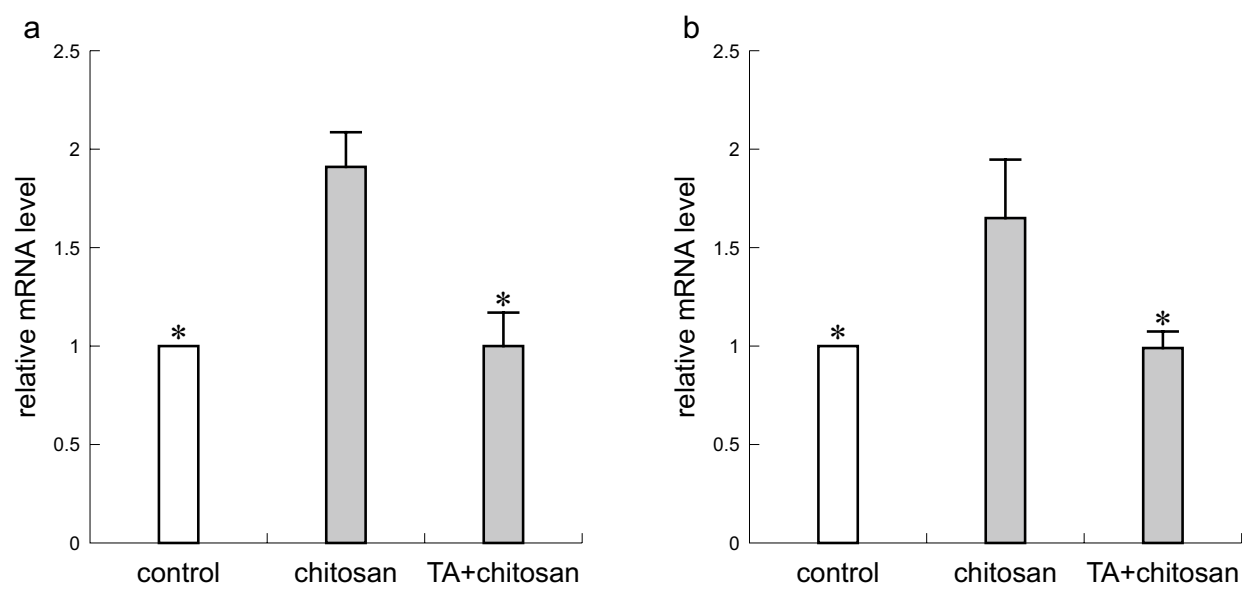

Fig. 3. The effect of pre-treatment with a $0.001 \%$ of $\mathrm{TA}$ on the expression of IL-8 mRNA in HSC-2 cells stimulated by a $0.025 \%$ of chitosan for $2 \mathrm{hrs}$ (a) and $4 \mathrm{hrs}$ (b). The data are the means \pm SD of triplicate assays. $* P$-value of $<0.05$ compared to the controls (unstimulated and chitosan polymer groups). The similar inhibition of IL- 8 mRNA was observed by both hours of incubation. 


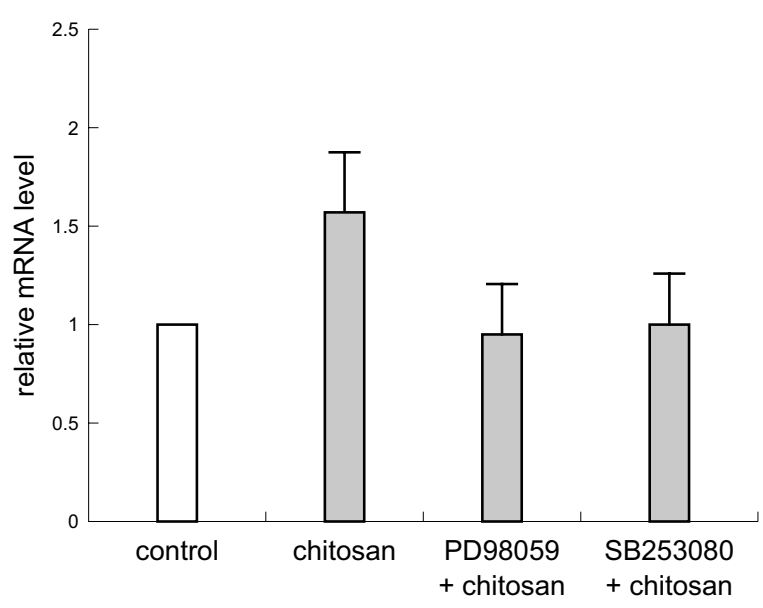

Fig. 4. The effect of pre-treatment for 2 hrs with PD98059 or SB203580 on the expression of IL-8 mRNA in HSC-2 cells stimulated by chitosan for $4 \mathrm{hrs}$. The data are the mean \pm SD of the triplicate assays. Both inhibitors induced the effective inhibition of IL-8 mRNA.

and Akt pan were 1.8, 1.3, 1.6, 1.3, 1.8, 1.4, 2.2, 1.6, 1.5, 1.6, $1.3,1.7,1.6,1.8,1.2$, respectively. Twelve kinases exhibited a difference ratio between $\mathrm{TA}+$ the chitosan group and the chitosan group of $\leq 0.8$. The ratios of JNK3, MSK2, p38g, p38d, p38a, RSK2, GSK-3a/b, GSK-3b, Akt1, Akt2, Akt3, and Akt pan were $0.8,0.6,0.7,0.8,0.8,0.8,0.5,0.8,0.6,0.7$, $0.7,0.6$, respectively.

\section{Discussion}

The information thus obtained is a fairly accurate representation of the in vivo situation as cytokine production profiles can be assessed in freshly obtained cells that have been activated in vitro for several hours (22). The detection of intracellular cytokine, such as observed in the present study by flow cytometry, is a rapid, easy and semiquantitative assay for screening homogenous cells in order to determine their cytokine pattern (23).

Pre-treating HSC-2 cells with either PD98059 or SB203580 before the chitosan application reduced the IL-8 mRNA expression level. This finding strongly indicates that chitosan-induced IL-8 production in epithelial cells is mediated through MAPK pathways. In addition, chitosan regulates epithelial and mesenchchymal cells via stimulation similar to the regulation by ultraviolet radiation (9), IkBa ubiquitination (18), and lipopolysaccharides (19). The inflamed gingival epithelium is severely infiltrated with leukocytes around the periodontal pocket, accompanied by an elevated expression of IL-8 (24). Thereafter, one of epithelial cell line, HSC-2 was used in this study because cystein proteinases from Porphyromonas gingivalis, or gingipains which are key virulence factors of periodontal diseases preferentially suppress IL-8, thus resulting in the attenuation of the cellular recognition in HSC-2 cells of bacteria (25). Chemokines, such as IL-8, form the first line of host defense for lysosomal enzymes and superoxide anion generation (26), thus indicating that this mechanism plays an important role in innate immunity.
The combined biological application of chitosan and TA is mainly for TA adsorption and TA release into or from chitosan, respectively (27-28). This study is the first to report that TA has an inhibitory effect on chitosan polymerinduced IL-8 production, which may be beneficial for clinical applications. This means that the mild inhibition of IL-8 production could thus be achieved at the initial inflammatory sites of the oral epithelium. The chitosan application to the gingival abscess and periodontal pockets has been clinically carried out for wound healing (personal communications).

Natural products have been investigated more thoroughly than chemical agents as promising agents to prevent inflammatory diseases, in general (29-31), and plaquerelated oral lesions, such as caries (32-33). There are many natural nitrogen-containing organic compounds that possess biological activities. For example, the amino group containing nitrogen is exposed to various degrees of deacetylation of chitin. Chitosan is a biocompatible and biodegradable material. After the chemotactic accumulation of inflammatory cells through IL-8 production, chitosan plays a role in the reorganization of the extracellular matrix during the final stage of wound healing (34-36). These phenomena are thought to also occur in the oral mucosa. Therefore, the inhibition of the initial inflammatory reaction after applying chitosan is beneficial with respect to its clinical application. The TA-induced inhibitory reaction to epithelial cells also induces the reduction of cytokine production by gingival fibroblasts.

In addition, the present study investigated whether or not a bioactive natural product, TA, regulates and affects the p38 MAPK and ERK signaling pathways. The TA group showed that IL-8 mRNA expression of TA and the chitosan group was reduced in comparison to the chitosan polymer group. In this study, the antibody assay for the phosphorylation of MAPKs showed that the pre-treatment effects of TA on the chitosan-induced IL- 8 production were mediated mainly through the inhibition of the p38 MAPK pathways. The family of p38 MAPKs (p38a, p38b, p38d, and p38g) are mainly activated by cellular stress and inflammatory cytokines, although they also regulate non-stress-related functions such as proliferation, differentiation and development (37-39). GSK-3b was originally identified as a negative regulator of glycogen synthase in insulin-responsive tissues (40). GSK-3 is ubiquitiously expressed and it demonstrates basal catalytic activity in cells. Following the stimulation with agonists, the inactivation of GSK-3 occurs through the phosphorylation of several residues and this is mediated by a variety of upstream kinases. In this regard, one of the most studied GSK-3b upstream kinases is Akt (41-42). The present antibody study clearly supports this intimate relationship between Akt and GSK. MSK1/2s are nuclear kinases that act downstream of the MAPK/ERK pathways (43-44). Recently, these kinases have been shown to be mandatory for the stress-induced phosphorylation of histone $\mathrm{H} 3-\mathrm{Ser}^{10}$ and for the transcriptional activation of several immediate early genes (45). The present data demonstrate the signal transduction pathways, from upstream 
to downstream, through ERK, p38, Akt, GSK, and MSK. Furthermore, the sub-cellular inhibitory effect of TA on the chitosan polymer-induced IL-8 production in cultured epithelial cells is mediated via the Akt-rich signal pathways.

Sponge-type chitosan may be applied to wound healing in the oral mucosa, gingiva, and periodontal pocket. The chitosan monomer acts as a biocompatible, stable medicament even at the initial stage of wound healing because of the minimum inflammatory reaction in comparison to the application of the chitosan polymer (46). However, as the physical properties of chitosan monomer are very poor and easily dissolvable, it could not be used as a scaffold and as a carrier material. Therefore, if the initial chemotactic activity of the chitosan polymer is inhibited, its clinical application such as wound dressing may be popularized more safely.

In conclusion, the present study demonstrates that pretreatment with TA may reduce the intracellular IL-8 production in HSC-2 cells via the MAPK signaling pathways. These findings indicate that the combined application of both TA and chitosan may be clinically beneficial treatment for inflammatory lesions in the oral mucosa.

\section{References}

1. Asaoka K. Chitin/Chitosan, the Choice Food Supplement for Over 10,000 Physicians in Japan. Vantage Press, New York, 1996; 143.

2. Koide SS. Chitin-chitosan: Properties, benefits and risks. Nutr Res 1998; 18: 1091-101.

3. Shigemasa Y, Saito K, Sashiwa H, Saimoto H. Enzymatic degradation of chitins and partially deacetylated chitins. Int J Biol Macromol 1994; 16: 43-6.

4. Muzzarelli RAA, Mattioli-Belmonte M, Pugnaloni A, Biagini G. Biochemistry, histology and clinical use of chitins and chitosans in wound healing. In: Jolles P, Muzzarelli RAA ed. Chitin and Chitinases. Birkhauser Verlag, Basel, 1999; 285-93.

5. Shigemasa Y, Minami S. Application of chitin and chitosan for biomaterials. Biotech Genet Eng Rev 1996; 13: 383-420.

6. Ikeda T, Yanagiguchi K, Viloria IL, Hayashi Y. Relationship between lysozyme activity and clinical symptoms following the application of chitin/chitosan in endodontic treatment. In: Muzzarelli RAA ed. Chitosan Per Os: From Dietary Supplement to Drug Carrier. Atec Edizioni, Crottammare, 2000; 275-92.

7. Mori, T., Okumura M, Matsuura M, et al. Effects of chitin and its derivatives on the proliferation and cytokine production of fibroblasts in vitro. Biomaterials 1997; 18: 947-51.

8. Mori T, Irie Y, Nishimura S, et al. Endothelial cell responses to chitin and its derivatives. J Biomed Mater Res 1997; 43B: 469-72.

9. Hubert-Buron A, Leblond J, Jacquot A, Duceotte P, Dechelotte P, Coeffier M. Glutamine pretreatment reduces IL-8 production in human intestinal epithelial cells by limiting IkBa ubiquitination. J Nutr 2006; 136: 1461-5.

10. Ueno H, Yamada H, Tanaka I, et al. Accelerating effects of chitosan for healing at early phase of experimental open wound in dogs. Biomaterials 1999; 20: 1407-14.

11. Uchida $\mathrm{Y}$, Shiba $\mathrm{H}$, Komatsuzawa $\mathrm{H}$, et al. Expression of IL-1 $\beta$ and IL-8 by human gingival epithelial cells in response to Actinobacillus actinomycetemcomitans. Cytokine 2001; 14: 152-61.

12. laube DM, Dongari-Bagtsolou A, Kashleva H, Eskdale J, Gallagher G, Diamond G. Differential regulation of innate immune response genes in gingival epithelial cells stimulated with Aggregatibacter actinomycetemcomitans. $J$ Periodontal Res 2008; 43: 116-23.

13. Lu Jk, Prudhommeaux F, Meunier A, Sedel L, Guillemin G. Effects of chitosan on rat knee cartilages. Biomaterials 1999; 20: 1937-44.

14. Densler HL. Gerrish KE, Williams T, Rao G, Kittelson J. Prevention of photocarcinogenesis and UV-induced immunosuppression in mice by topical tannic acid. Nutr Cancer 1994; 22: 121-30.

15. Noro T, Ohki $\mathrm{T}$, Noda $\mathrm{Y}$, et al. Inhibitory effects of hydrolysable tannins on tumor promoting activities induced by 12-O-tetradecanoyl-phorbol-13-acetate (TPA) in JB6 mouse epidermal cells. Basic Life Sci 1999; 66: 665-73.

16. Erdelyi K, Kiss A, Bakondi E, et al. Gallotannin inhibits the expression of chemokines and inflammatory cytokines in A549 cells. Mol Pharmacol 2005; 68: 895-904.

17. Afaq F, Saleem M, Krueger CG, Reed JD, Mukhtar H. Anthocyanin- and hydrolysable tannin-rich pomegranata fruit extract modulates MAPK and NF-kappaB pathways and inhibits skin tumorigenesis in CD-1 mice. Int J Cancer 2005; 113: 423-33.

18. Park HJ, Kim HJ, Know HJ, et al. UVB-induced interleukin-18 production is down regulated by tannic acids in human HaCaT keratinocytes. Exp Dermatol 2006; 15: 589-95.

19. Bodet C, Chandad F, Grenier D. Cranberry components inhibit interleukin-6, interleukin-8, and prostagrandin E2 production by lipopolysaccharide-activated gingival fibroblasts. Eur J Oral Sci 2007; 115: 64-70.

20. Lee H-J, Lee J, Lee S-K, Lee S-K, Kim E-C. Differential regulation of iron chelator-induced IL-8 synthesis via MAP kinase and NF-kB in immortalized and malignant oral keratinocytes. BMC Cancer 2007; 7: 176. DOI:10.1186/ 1471-2407-7-176.

21. Ganno T, Yamada S, Ohara N, et al. Early gene expression analyzed by cDNA microarray and real-time PCR in osteoblasts cultured with chitosan monomer. J Biomed Mater Res 2007; 82A: 188-94.

22. Krouweis FH, Nocker RET, Snoek Mlutter R, Van Der Zee JS. Immunocytochemical and flow cytofluorimetric detection of intracellular IL-4, IL-6 and IFN-g: applications using blood- and airway-derived cells. J Immunol Methods 1997; 203: 89-101.

23. Jung T, Schauer U, Heusser C, Neumann C, Rieger C. Detection of intracellular cytokines by flow cytometer. $J$ Immunol Methods 1993; 159: 197-207.

24. Liu RK, Cao CF, Meng HX, Gao Y. Polymorphonuclear neutrophils and their mediators in tissues from generalized aggressive periodontitis. J Periodontol 2001; 72: 1545-53.

25. Uehara A, Naito M, Imamura T, Potempa J, et al. Dual regulation of interleukin- 8 production in human oral 
epithelial cells upon stimulation with gingipains from Porphyromonas gingivalis. J Med Microbiol 2008; 57: 500-7.

26. Weiss SJ. Tissue destruction by neutrophils. New Engl J Med 1989; 320: 365-76.

27. Chang M-Y, Juang R-S. Adsorption of tannic acid, humic acid, and dyes from water using the composite of chitosan and activated clay. J Collod Interface Sci 2004; 278: 18-25.

28. Aelenei N, Popa MI, Novac O, Lisa G, Balaita L. Tannic acid incorporation in chitosan-based microparticle and in vivo controlled release. J Mater Sci Mater Med 2009; 20: 1095-102.

29. Iauk L, Ragusa S, Rapisarda A, Franco S, Nicholosi VM. In vitro antimicrobial activity of Pistacia lentiscus L. extracts: preliminary report. J Chemother 1996; 8: 207-9.

30. Al-Said MS, Ageel AM, Parmas NS, Tariq M. Evaluation of gastric and duodental anti-ulcer activity. J Ethnopharmacol 1986; 15: 271-8.

31. Huwez FU, Al-Habbal MJ. Mastic in treatment of benign gastric ulcers. Gastroenterol Jpn 1986; 21: 273-4.

32. Cai L, Wu CD. Compounds from Syzgium aromaticum possessing growth inhibitory activity against oral pathogens. J Nat Prod 1996; 59: 987-90.

33. Aksoy A, Duran N, Koksal F. In vitro and in vivo antimicrobial effects of mastic chewing gum against Streptococcus mutans and mutans streptococci. Archs Oral Biol 2006; 51: 476-81.

34. Peluso G, Perillo O, Ranieri M, et al. Chitosan-mediated stimulation of macrophage function. Biomaterials 1994; 15: $1215-20$.

35. Usami Y, Okamoto Y, Minami S, et al. Chitin and chitosan induce migration of bovine polymorphonuclear cells. $J$ Vet Med Sci 1994; 56: 761-2.
36. Minami S, Masuda M, Suzuki H, et al. Subcutaneous injected chitosan induces systemic activation in dogs. Carbohydr Polym 1997; 33: 285-94.

37. Nebreda AR, Porras A. p38 MAP kinases: beyond the stress response. Trends Biochem Sci 2000; 25: 257-60.

38. Cuenda A, Rousseau S. p38 MAP-kinases pathway regulation, function and role in human diseases. Biochem Biophys Acta 2007; 1773: 1358-75.

39. Hui L, Bakiri L, Stepniak E, Wagner EF. P38 alpha: a suppressor of cell proliferation and tumorigenesis. Cell Cycle 2007; 6: 2429-33.

40. Yoeli-Lerner M, Chin YR, Hansen CK, Toker A. AKT/ protein kinase B and Glycogen synthase kinase-3b signaling pathway regulates cell migration through the NFAT1 transcription factor. Mol Cancer Res 2009; 7: 425-32.

41. Manning BD, Cantley LC. AKT/PKB signaling: navigating downstream. Cell 2007; 129: 1261-74.

42. Ivetac I, Gurung R, Hakim S, et al. Regulation of PI(3)K/ Akt signaling and cellular transformation by inositol polyphosphate 4-phosphatase-1. EMBO Rep 2009; 10: 487-93.

43. Arthur JS. MSK activation and physiological roles. Front Biosci 2008; 13: 5866-5879.

44. Ananieva O, Darragh J, Johansen C, et al. The kinases MSK1 and MSK2 act as negative regulators of Toll-like receptor signaling. Nature Immunol 2008; 9: 1028-35.

45. Duncan EA, Anest V, Cogswell P, Baldwin AS. The kinases MSK1 and MSK2 are required for epidermal growth factorinduced, but not tumor necrosis factor-induced histon H3 Ser10 phosphorylation. J Biol Chem 2006; 281: 12521-25.

46. Matsunaga T, Yanagiguchi K, Yamada S, Ohara N, Ikeda T, Hayashi Y. Chitosan monomer promotes tissue regeneration on dental pulp wounds. J Biomed Mater Res 2006; 76A: 711-20. 